\title{
Learning Agility as a Predictor of High Performance and Potential: A Case study from Healthcare Industry
}

\author{
Edìte Kalnina, Riga Technical University
}

\section{INTRODUCTION}

Term "learning agility" was first introduced by Lombardo and Eichinger (2000). It is defined as the willingness and ability to learn from experiences, and subsequently apply that learning in new situations to perform successfully under new or first-time situations. Learning agility is heavily used for talent assessment and development and succession planning in multinationals worldwide, but for Latvian local companies it is not yet a daily human resources practice. Very little scholarly research has been conducted on this construct worldwide and in Latvia. In the turbulent business environment, the company leaders need to be more agile than ever. Leaders should adapt to new business strategies, working across cultures and dealing with virtual teams.

Various studies suggest that learning agility is a better predictor of high performance. Connolly \& Viswesvaran (2002) suggests learning agility is a better predictor of high performance as compared to IQ and personality traits. It has also been found that learning agile leaders are more successful in dynamic, turbulent workplaces (Dai, De Meuse, \& Tang, 2013). There are five major factors of learning agility - mental agility, people agility, change agility, results agility and self-awareness (Swisher et al., 2013). As described by Mitchinson \& Morris (2012) at Columbia University research there are four behaviors that enable learning agility (innovating, performing, reflecting and risking) and one that derails it (defending). In the same study no significant differences were found in learning agility scores across gender, age or organizational level.

The scientific support of a linkage between learning agility and leadership seems to be scanty. Results of a meta-analysis by De Meuss (2019) show learning agility has a robust relationship with both leader performance $(=0.74)$ and potential $(=0.75)$. In this study it was hypothesized that learning agility will be positively related to annual performance ratings.

\section{MATERIAL AND METHODS}

The author was reviewing talent management process for three consecutive years - 2011, 2012, 2013 - and high potential employee identification for a local branch of a global innovative pharmaceutical company in Latvia. The company has a solid talent management process in place and devotes time and resources to the development of identified talents. Up to three times a year, Talking Review sessions are conducted to identify and develop their high potential employees around the world.

Talking Review is a facilitated session where people managers openly discuss and calibrate talented employees in terms of performance, potential, readiness, willingness, and mobility. During a typical session, line managers carefully assesses candidates using a 9-cell performance-potential matrix (see figure below). Each candidate is placed in a cell based on ratings of their performance during the past years and a discussion revolving their perceived level of learning agility.

The researcher collected learning agility scores and annual performance ratings on 33 managers located in Latvia. A mean performance rating was computed based on the three years - all 33 employees were at managerial level.

\section{RESULTS}

A positive relationship between learning agility and ratings of performance was observed. It was observed that the percentage of candidates classified as highly learning agile increased over time, ranging from $16 \%$ (2011) to $22 \%$ (2012) to 18\% (2013). It suggests that as the company implemented the Talking Review process, decision makers learned from their experiences, calibrated their evaluations, and improved their accuracy in identifying their high potentials candidates.

\section{DISCUSSION}

The case study certainly holds several practical implications for the researchers as well as the practitioners. There are need for empirical studies to be conducted in this area. Caution should be exercised before drawing firm conclusions about these findings since the study included no controls for a manager's commitment to change, the extent of the line manager's support for such change, or the culture and structure of the organization and its possible influence on learning agility. Regression to the mean also might have played a role in the results.

\section{CONCLUSIONS}

The present paper and case study is an attempt to explore the relationship between learning agility and high performance. A positive relationship between learning agility and ratings of performance was observed. This understanding of the relationships among all these factors will further add to the existing knowledge on these constructs and help the organizations to execute leadership assessment in a better way.

Scholars should provide new ideas for understanding and conceptualizing learning agility. Human resources professionals and executives in organizations should provide access to high-potential employee data and performance, so a more rigorous process can be applied to understanding the linkage between learning agility and leader success (or derailment).

\section{KEYWORDS}

Learning agility, talent management, leadership development, succession planning 